\title{
A Brief Review on the Effect of Global Warming onEcosystem
}

\author{
Souvik Bera ${ }^{1}$, Debarghya Basak ${ }^{1}$, Anubhav Chatterjee ${ }^{1}$, SanjimaPal $^{1}$, Ronit Biswas ${ }^{1}$, \\ Sayantan $\mathrm{Sil}^{1} *$ and Tanay Pramanik ${ }^{1}$. \\ ${ }^{1}$ University of Engineering and Management, University Area, Action Area III, B/5, \\ Newtown,Kolkata-700160, India
}

\begin{abstract}
:
The concentrationof several greenhouse gases has increased over time. The ongoing accumulation of greenhouse gases causes increase in global warming. Experts in fields from forestry to economics, even national security experts, pitched in to assess the range of possible consequences. The unfortunate reality is that predicting the impact of global warming is notoriously hard. It brings a whole range of scientific disciplines together, such as oceanography, meteorology, and geology, while no one can agree on the exact impacts for specific regions of the world. All scientists agree global warming will have numerous negative effects on our planet and our way of life.
\end{abstract}

Kev Words: Global Warming, Climate change, Environmental change, temperature. 


\section{Introduction:}

Global warming is the increase in the average temperature of Earth's nearsurface air and oceans since the mid-20th century. According to the 2007 Fourth Assessment Report by the Intergovernmental Panel on Climate Change (IPCC), global surface temperature has been increased $0.74 \pm$ $0.18{ }^{\circ} \mathrm{C}\left(1.33 \pm 0.32{ }^{\circ} \mathrm{F}\right)$ during the 20th century. Temperature increase from the middle of the 20th century has been caused by increasing concentrations of greenhouse gases, which result from human activity such as the burning of fossil fuel and deforestation. Projections in the latest IPCC report indicate that the global surface temperature is likely to rise a further 1.1 to $6.4{ }^{\circ} \mathrm{C}$ (2.0 to 11.5 $\left.{ }^{\circ} \mathrm{F}\right)$ during the 21 st century. Increase in global temperature will cause sea levels to rise and will change the amount and pattern of precipitation.

Warming is expected to be strongest in the Arctic and would be associated with continuing retreat of glaciers, permafrost and sea ice. The Kyoto Protocol is aimed at stabilizing greenhouse gas concentration to prevent a "dangerous anthropogenic interference". As of November 2009, 187 states had signed and ratified the protocol.

More or less all specialists studying the climate record of the earth have the same opinion now that human actions, mainly the discharge of greenhouse gases from smokestacks, vehiclesandburningforestsar eperhapstheleadingpowerdrivingthefashio

n.

\section{Material and Methods}

Temperature Variations: Warming of the climate system includes observed increases in global average air and ocean temperatures, widespread melting of snow and ice, and rising global average sea level. NASA's Goddard Institute for Space Studies (GISS) and the National Climatic Data Centre show that 2005 was the warmest year since reliable, widespread instrumental measurements became available in the late 19th century, exceeding the previous record set in 1998 by a few hundredths of a degree. The effect of changes in solar forcing in recent decades is uncertain, but small, with some studies showing a slight coolingeffect, whileothersstudiessuggestas lightwarmingeffect.Greenhousegasesands olar forcing affect temperatures in different ways. While both increased solar activity and increased greenhouse gases are expected to warmthe troposphere, an increase in solar activity should warm the stratosphere while an increase in greenhouse gases should cool the stratosphere. Observations show that temperatures in the stratosphere have 
been cooling since 1979, when satellite measurements became available. Weather balloon data from the pre- satellite era show cooling since 1958, though there is greater uncertainty in the early radiosonderecord.

\section{Annual Greenhouse Gas Index}

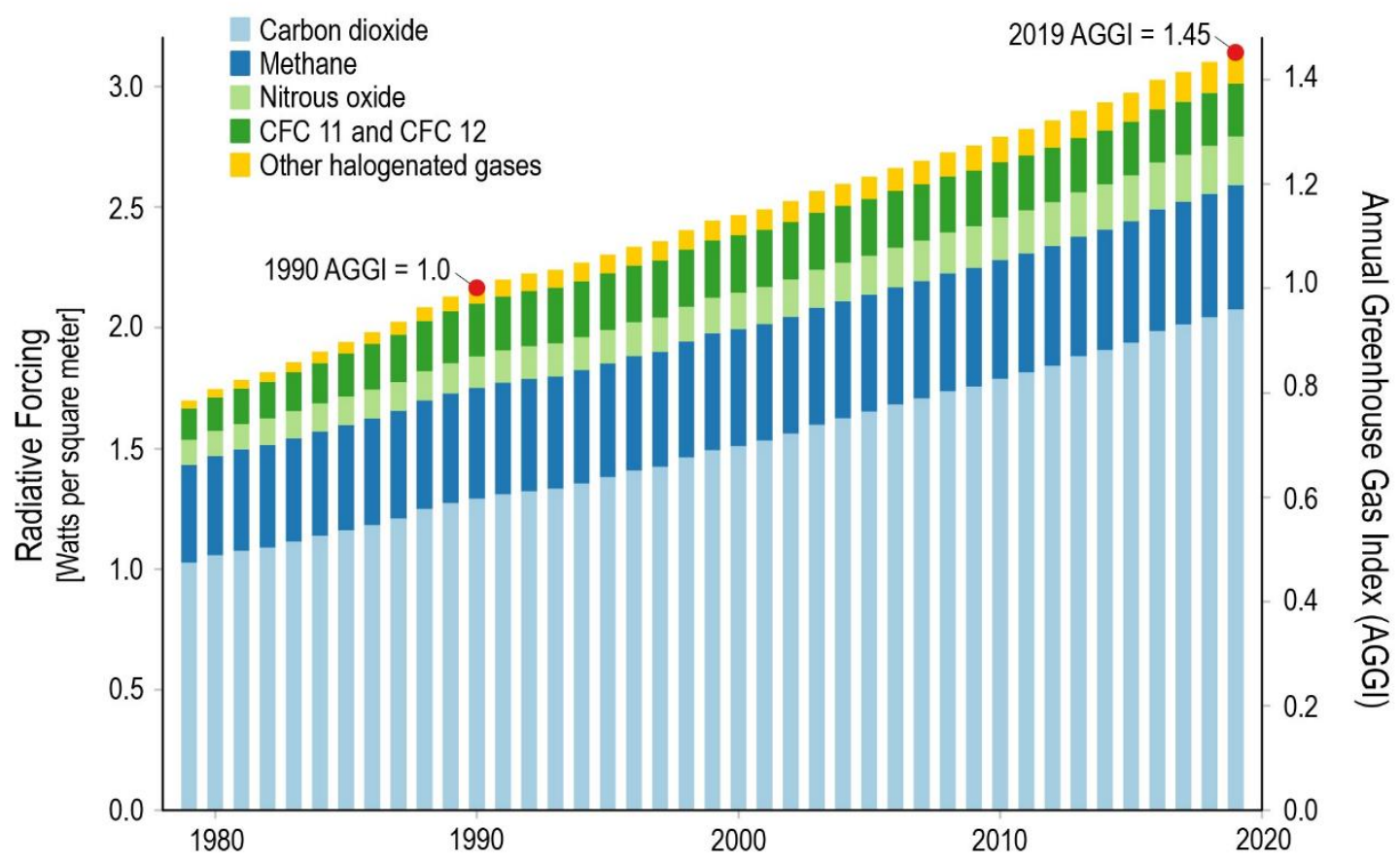

The annual greenhouse gas index is given in the above figure. The greenhouse effect is the process by which absorption and emission of infrared radiation by gases in the atmosphere warm a planet's lower atmosphere and surface. It was proposed by Joseph Fourier in 1824 and was first investigated quantitatively by Svante Arrhenius in 1896. The question in terms of global warming is how the strength of the presumed greenhouse effect changes when human activity increases the concentrations of greenhouse gases in the atmosphere. The greenhouse gases like carbon dioxide, methane, and nitrous oxide are playing hazards in the presenttimes. Thesegreenhousegasestraph eatinearth'satmosphereandthusresultininc reasing the temperature of earth. The excessive emission of these gases is one of the major Causes of Global Warming. The major source of carbon dioxide is the power plants. These power plants emit large amounts of carbon dioxide produced from burning of fossil fuels for the purpose of electricity generation. The impact of increased surface temperatures is significant in itself. But global warming will have additional, far- 
reaching effects on the planet. Warming modifies rainfall patterns, amplifies coastal erosion, lengthens the growing season in some regions, melts ice caps and glaciers, and alters the ranges of some infectious diseases. Some of these changes are alreadyoccurring.

\section{Climate Change:}

For most places, global warming will result in more frequent hot days and fewer cool days, with the greatest apart from driving temperatures up, global warming is likely to cause bigger, more destructive storms, leading to an overall increase in precipitation. With some

exceptions, the tropics will likely receive less rain (orange) as the planet warms, while the polar region will receive more precipitation (green) 7. White areas indicate that less than two-thirds of the climate models agreed on how precipitation willchange.

\section{Rising Sea Levels:}

The weather isn't the only thing global warming will impact; rising sea levels will erode coasts and cause more frequent coastal flooding. Some island nations will disappear. The problem is serious because up to 10 percent of the world's population lives in vulnerable areas which are less than 10 meters (about 30 feet) abovesealevel Between1870 and2000,thesealevelincreasedby $1.7 \mathrm{millim}$ etersperyearonaverage,foratotalsealevel 


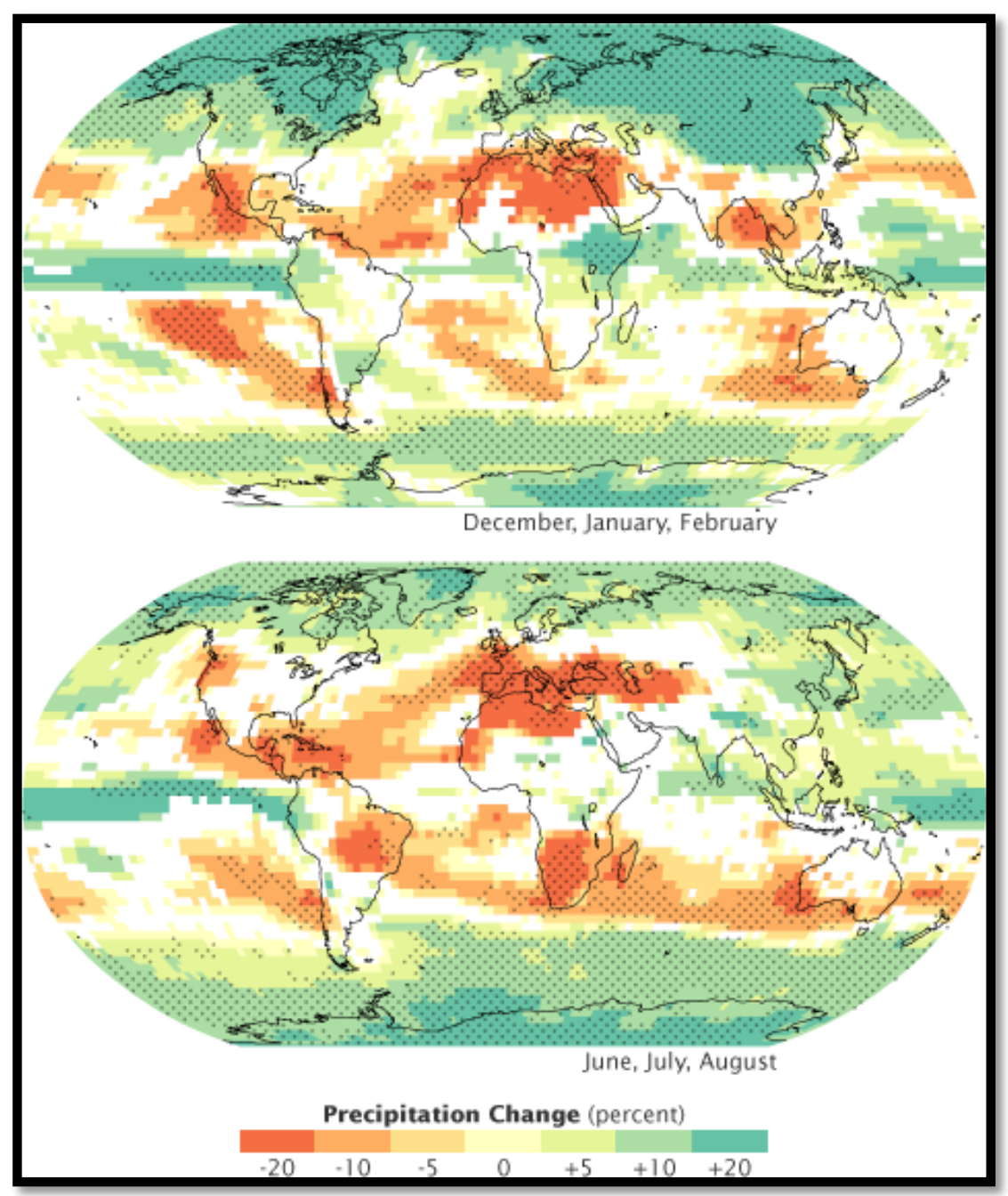

Fig-2: Variation of precipitation due to global warming 
rise of 221 millimeters $(0.7$ feet or 8.7 inches). And the rate of sea level rise is accelerating. Since 1993, NASA satellites have shown that sea levels are rising more quickly, about 3 millimeters per year, for a total sea level rise of 48 millimeters (0.16 feet or 1.89 inches) between 1993 and 2009.

It is impossible to pin any single unusual weather event on global warming, but emerging evidence suggests that global warming is already influencing the weather. Heat waves, droughts, and intense rain events have increased in frequency during the last 50 years, and human-induced global warming more likely than not contributed to the trend. Sea levels crept up about 20 centimeters (7.9 inches) during the twentieth century Sea levels are predicted to go up between 18 and $59 \mathrm{~cm}$ (7.1 and 23 inches) over the next century, though the increase could be greater if ice sheets in Greenland and Antarctica melt more quickly than predicted. Higher sea levels will erode coastlines and cause more frequent flooding. The year wise change of sea level is shown in figure-3.

\section{SATELLITE DATA: 1993-PRESENT}

Data source: Satellite sea level observations.

Credit: NASA's Goddard Space Flight Center

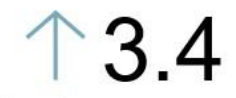

millimeters per year

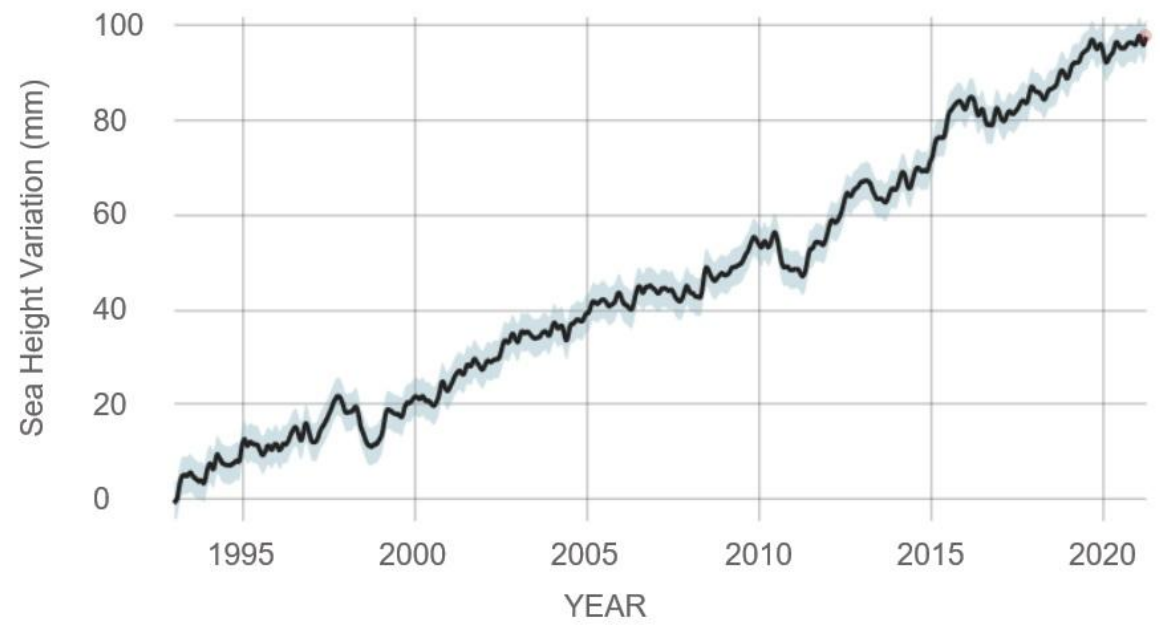

Fig-3: Year wise increase in sea level 


\section{Disappearing Islands:}

The Majuro Atoll in the Pacific Marshall Islands is projected to lose $80 \%$ of its land with a 20 -inch $(0.5 \mathrm{~m})$ rise in sea level. Many of the islands will simply disappear under the rising seas. A similar fate awaits other islands throughout the South Pacific and Indian Oceans, including many in the Maldives and French Polynesia. Coral reefs, which protect many of these islands, will be submerged, subjecting the local peoples to heightened storm surges and disrupted coastal ecosystems. Tourism and local agriculture will be severely challenged.Oneofthepoorestnationsinthe worldisprojectedtolose $17.5 \%$ ofitslandifse alevel rises about 40 inches $(1 \mathrm{~m})$. Tens of thousands of people are likely to be displaced, and the country's agricultural system will be adversely affected. Coastal flooding will threaten animals, plants, and fresh water supplies. The current danger posed by storm surges when cyclones hit Bangladesh is likely toincrease.

\section{Disappearing Ice Packs:}

Wildlife in the arctic regions will be seriously affected as warmer temperatures affect the ocean ice cover. Polar bears rely on sea ice to hunt seals, which use the ice for rearing their young. The native peoples also rely on the ice to hunt these species and walruses. Observations of walrus in 1996-99 showed them to be thin and in poor condition, partly due to receding sea ice.

\section{Increased Air Pollution:}

Three out of four of the world's highestdensity cities are in rapidly developing countries, where vehicle pollution is high. In Central Europe alone 21,000 deaths are tied to air pollution each year. The concentration of photochemical pollutants, such as ozone, tends to increase with warmer temperatures. Ozone damages lung tissue and is especially harmful to people with asthma and other lungconditions.

\section{Impacting Ecosystems:}

More importantly, perhaps, global warming is already putting pressure on ecosystems, the plants and animals that co-exist in a particular climate zone, both on land and in the ocean. Warmer temperatures have already shifted the growing season in many parts of the globe. The growing season in parts of the Northern Hemisphere became two weeks longer in the second half of the 20th century. Spring is coming earlier in both hemispheres. This change in the growing season affects the broader ecosystem. Migrating animals have to start seeking food sources earlier. The shift in seasons 
may already be causing the lifecycles of pollinators, like bees, to be out of synch with flowering plants and trees10. This mismatch can limit the ability of both pollinators and plants to survive and reproduce, which would reduce food availability throughout the food chain. Warmer temperatures also extend the growing season. This means that plants need more water to keep growing throughout the season or they will dry out, increasing the risk of failed crops and wildfires. Once the growing season ends, shorter and milder winters fail to kill dormant insects, increasing the risk of large and damaging infestations in subsequentseasons.

\section{Effects of Global Warming on Water}

\section{Resources:}

Both the environment and the human lives are being adversely affected by the phenomenon of global warming. The effects of global warming is myriad and numerous. Several researches were conducted by different organizations and all of them revealed that global warming is increasing at an alarming rate. Effects of global warming are vast and cover every sphere of one's life. Both the nature and the living beings are suffering from the effects of global warming. If we do not take note of the alarming rate of growing global warming, then our earth might cease to exist someday. The water resources have been heavily affected by the global warming phenomenon. Sea levels have risen, glaciers retreats are taking place often and the most harmful affect is the shrinking of the Arctic Circle. This International Research Journal of Environment Sciences_ ISSN 2319-1414 Vol. 1(4), 56-59, November (2012) Int. Res. J. Environment Sci. International Science Congress Association 59 phenomenon has caused concerns among all the sectors and geoengineering is considered to be a way of mitigation. If we put it simply then the water bodies would be affected during the long and scorching summers since the rate of evaporation would increases with hotter summers. Water cycle is important for any kind of human activity and global warming would adversely affect this cycle in the human activities as well as the climactic changes. Global warming might also lead to floods. The water levels in many regions would lower due to excessive evaporation and this would cause in torrential downpours increasing the chance of deluge12. The acceleration in the phenomenon of global warming has caused the ice sheets in the West Antarctic Circle and Greenland to shrink. Carbon sediments have been released in the air and due to the increase of carbon emission the reduction in the ice sheets 
has taken place. This reduction might cause a huge flood around the world. By the end of twenty first century the water in the sea is expected to rise by 7.1- 23.2 inches. Due to the augmentation of global warming effects the Thermohaline circulation might as well get disrupted.
The fresh water from the Polar Regions would interrupt the Gulf Stream causing this distress. The implication of a change of course of the Gulf Stream would have worldwide effect that would drastically accelerate climate change andextreme.

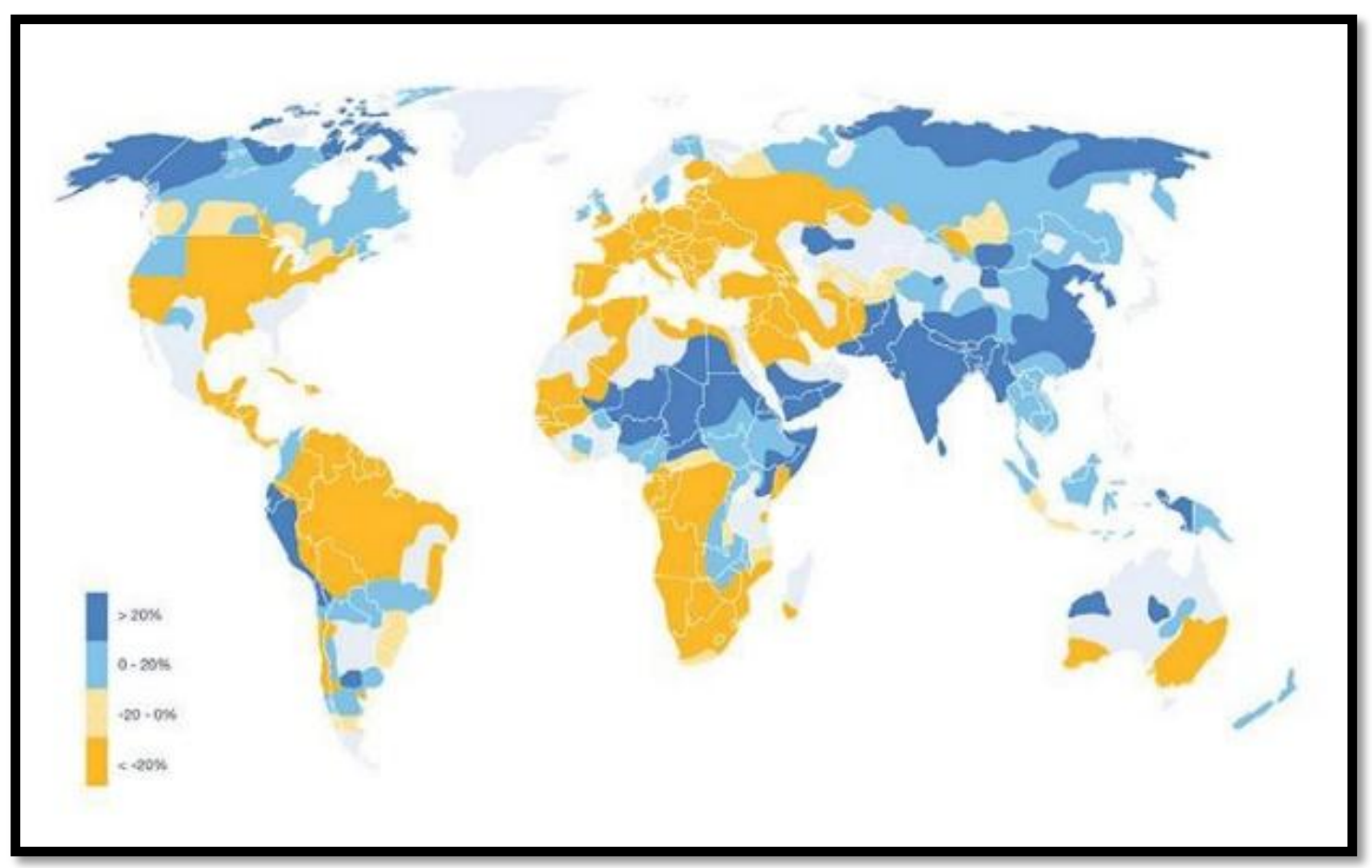

Fig-4: Change in water availability by 2050 in different part of the world ${ }^{5}$. 


\section{$\underline{\text { Conclusion }}$}

The impact of global warming is already being seen around the world. Despite efforts on behalf of some countries to reduce greenhouse gas emissions, such as the Kyoto treaty, the world asa whole is pumping out more and more carbon dioxide every year. Countries like Norway and Holland are meeting their goals to reduce emissions, but this is small fry when countries such as China and India are pumping out more and more every year. Reducing our carbon and greenhouse gas emissions will make our personal living space more sustainable. $\quad \mathrm{We}$ humankindhavetheabilitytodestroytheplan et,wecanalsohelpprotectandsustainit.

\section{$\underline{\text { References }}$}

1. Kyoto Protocol: Status of Ratification, United Nations Framework Convention on Climate Change (1998).

2. IPCC (2007-05-04), Summary for Policymakers, Climate Change 2007: The Physical Science Basis. Contribution of Working Group I to the Fourth Assessment Report of the Intergovernmental Panel on Climate Change(2007).

3. Gabriele C.H., Understanding and Attributing Climate Change, The Physical Science Basis Contribution of Working Group I to the Fourth Assessment Report of the Intergovernmental Panel on Climate Change(2007).

4. Weart Spencer, The Carbon Dioxide Greenhouse Effect, The Discovery of Global Warming, American Institute of Physics(2008)

5. https://www.grida.no/resources/5639 